\title{
Study of cutting force and tool wear during turning of aluminium with WC, PCD and HFCVD coated MCD tools
}

\author{
Sisira Kanta Pattnaik, Minaketan Behera, Sachidananda Padhi, Pusparaj Dash, and Saroj Kumar Sarangi \\ Department of Mechanical Engineering, VSSUT Burla, Sambalpur 768018, India
}

Received: 26 July 2020 / Accepted: 15 August 2020

\begin{abstract}
Enormous developmental work has been made in synthesis of metastable diamond by hot filament chemical vapor deposition (HFCVD) method. In this paper, micro-crystalline diamond (MCD) was deposited on WC- 6 wt.\% Co cutting tool inserts by HFCVD technique. The MCD coated tool was characterized by the scanning electron microscope (SEM), X-ray diffraction (XRD) and micro Raman spectroscopy ( $\mu$-RS). A comparison was made among the MCD tool, uncoated tungsten carbide (WC) tool and polycrystalline diamond (PCD) tool during the dry turning of rolled aluminum. The various major tests were conducted such as surface roughness, cutting force and tool wear, which were taken into consideration to establish a proper comparison among the advanced cutting tools. Surface roughness was measured during machining by Talysurf. The tool wear was studied by SEM after machining. The cutting forces were measured by Kistler 3Ddynamometer during the machining process. The test results indicate that, the CVD coated MCD tool and PCD tool produced almost similar results. But, the price of PCD tools are five times costlier than MCD tools. So, MCD tool would be a better alternative for machining of aluminium.
\end{abstract}

Keywords: HFCVD coating / turning of nonferrous / XRD / force measurement / surface roughness / wear

\section{Introduction}

Diamond is the hardest available material till date. It is very much popular due to its mechanical, thermal and chemical properties [1]. Rapid developmental works were carried out in the last three decades in the research area of CVD diamond coating. The low-pressure synthesis of diamond was reported for 1st time in 1961 (Eversole; Union carbide corporation) CVD is one of the important techniques to produce diamond on the substrate. The substrate might be a cutting tool or any commercial or medical application material. There are different CVD techniques like lowpressure CVD (LPCVD); atmospheric pressure CVD (APCVD) and plasma enhanced CVD (PECVD), etc. are there but among all. The LPCVD is very much popular and preferable technique to produce diamond, due to its excellent purity, uniformity and good step coverage [2]. The level of purity is very high in the LPCVD system as enough vacuum is maintained in the curved chamber (which is about $5-10$ Torr). So the chance of contamination is minimized. The deposition is with very good in LPCVD with uniform step coverage throughout the substrate. In the case of poor step coverage, there is very less deposition on the

\footnotetext{
* e-mail: sarojsarangi@gmail.com
}

side edges of the substrate which is very undesirable, so good step coverage is very much essential for the substrate, having complex geometry [3]. the low-pressure hot filament chemical vapor deposition (LPCVD) technique is having various advantages like very simple setup; low cost with less maintenance and highly versatile in nature due to these qualities. It is one of the preferable methods to deposit diamond. This LPHFCVD is simply also called as HFCVD. This HFCVD technique is a simple and cost-effective way to produce the diamond on the non-diamond substrate. Different hydrocarbons were utilized as carbon sources in HFCVD process and some commonly used hydrocarbons are like alkane series- methane, ethane, propane, butane, etc. $[4,5]$.

The diamond tool is in the form of microcrystal and widely used for nonferrous machining process. Tungsten carbide with $6 \%$ cobalt (WC-Co) is a suitable substrate material, where cobalt is used as a binding agent. Cobalt provides additional toughness to the tool material $[6,7]$. It is possible to grow diamond crystal on the non-diamond substrate like silicon wafer or molybdenum which was reported by Matsumoto et al. in 1982 [8].

The cobalt having a major drawback that, due to the presence of cobalt at the surface the diamond converts into graphite during the nucleation stage which is very undesirable. The Co has an adverse effect that at high 
temperature diamond has a tendency to convert into graphite. It acts as a catalyst for the graphitization of diamond. So it is very necessary to remove Co from the surface of the substrate. Small voids were formed due to the removal of the Co $[9,10]$. The voids, which formed on the tool surface will be filled with diamond powder during seeding, which will provide a suitable environment for the deposition of the diamond. There are various chemical etching techniques used for removing the Co binder from the substrate surface. Etching with Murakami reagent $\left(\mathrm{K}_{3} \mathrm{Fe}(\mathrm{CN})_{6}+\mathrm{KOH}+\mathrm{H}_{2} \mathrm{O}\right.$ in 1:1:10 volume ratio); etching using acid solution $\mathrm{HNO}_{3}: \mathrm{H}_{2} \mathrm{O}$ at 1:1 ratio is very much popular in recent trends. Multiple chemical etching is also adopted by many researchers by selective acids for better results $[11-14]$.

Nucleation is the initial and most critical stage during the synthesis of diamond. It directly influences the grain size, crystal structure, purity, etc. The carbon atoms can exist at different chemical bonds like, $\mathrm{sp}^{1}, \mathrm{sp}^{2}, \mathrm{sp}^{3}$ hybridization. But metastable CVD diamond consists of $\mathrm{sp}^{3}$ bonds (sigma bond) and is thermodynamically metastable. Several methods have been developed, that helps to increase nucleation density [15]. The cemented carbide (WC) substrates were chemically etched and then seeded with seeding powders such as diamond, CBN (Cubic Boron Nitride), or a-SiC powders. $\mathrm{CBN}$ or a-SiC seeding powders are chosen, because their similar crystal structure with diamond. Other abrasives also can be used for scratching such as silicates, nitrides, borides, aluminum oxides, CBN etc. It is again found that nucleation density decreases with the increase in particle size of the diamond abrasives [16-18]. So the particle size of the abrasives should be optimum and smaller in size are generally preferable. Tiny particles of the diamond are trapped in the void (which occurs due to chemical etching) present at the surface and act as seeds for diamond coating, due to which nucleation density increases to a greater extent. Carbon sources play a significant role in the nucleation and growth of the diamond. Organic carbon sources like acetone, ethanol, methanol-diethyl ether etc. also are capable for deposition of diamond and ten times faster than the hydrocarbons like methane and acetylene. Higher nucleation density is always desirable for a smooth and uniform diamond film [19-21]. Bias Enhanced Nucleation (BEN) is a very simple and preferable technique for nucleate more crystals. Bombardment of electrons on the surface of the substrate takes place only when a moderate positive voltage has supplied to the substrate and a negative voltage provided to the filament through external attachments $[22,23]$. Uniform and stable plasma discharge carryout when the negative ions attract towards the substrate with increase in bias voltage. So the decomposition of $\mathrm{H}_{2}$ and hydrocarbons on the substrate increase to a great extent. It becomes useful for nucleation of diamond on the nondiamond substrate with the reversed polarity (negative voltage is supplied to the substrate). The bombardment of positive ions occur on the surface of the substrate and good growth of diamond takes place (depth of diamond is about $20 \mu \mathrm{m} / \mathrm{h}$ ). It is not only useful for the hardness of the substrate material but also suitable for complex shapes. It is applicable for various substrate materials such as hexagonal GaN, silicon, platinum, Mo and $\mathrm{CoN}$ coated stainless steel, polycrystalline $\mathrm{Ni}$, nickel, 3C-SiC, copper, molybdenum. Machining of aluminium with different coated and uncoated tools were reported previously by many researchers. Aluminium is very much preferable as the work material due to its various mechanical properties. So it is very much used in automobile and aerospace industries [24-27]. Dry machining is one of the preferable approaches as it is a very economical and simple one with a comparison to the wet machining/minimum quantity lubrication technique [28]. However, machining aluminium with coated tool, specially diamond coated tool is now in recent trends. Diamond is one of the suitable tool material for machining aluminium due to its extreme hardness and chemically stable properties [29-33].

The natural diamond tool, synthetic single crystal diamond tools are very expensive. So for different industrial applications, they are not affordable. The necessity of diamond coated cutting tool with the same tool geometry is increasing to minimize the cost of the diamond tool [34-36]. The HFCVD coated diamond tool would be a better alternative. It is an easy, simple and cost-effective way to produce diamond on the WC substrate. In this paper, we produced a micro-crystalline diamond on WC cutting tool. We machined rolled aluminum to check the suitability of the coated tool. Two advanced cutting tools uncoated WC and PCD tools are also used for machining to establish a comparison among the cutting tools. The machining was performed at the same cutting condition for better comparision. The comparison between the CVD coated, uncoated and HPHT diamond (PCD) tool were made on the basis of cutting force, surface roughness and tool wear $[37,38]$. These three particulate cutting tools were chosen for comparison. Based on the results of all the cutting tools at all three aspects (surface finish, cutting force, tool wear) suitable tool was determined [39-41].

\section{Experimental setup and procedure}

The HFCVD coating unit was used for the deposition of diamond. It consists of a deposition chamber coupled with a rotary vacuum pump to maintain a sufficient vacuum. Besides that, it is having a heating unit, cooling unit, gas supply and control unit which is very well known. The deposition condition is mentioned in Table 1 . Cemented Carbide turning tool insert (WC, SPGN type) with $6 \%$ Co, K-10 series Sandvik Coromant, Sweden make was utilized as the substrate material. The nose radius of the WC tool and MCD tool are the same $0.8 \mathrm{~mm}$ whereas the PCD tool is having a nose radius of $0.4 \mathrm{~mm}$. The initial stage of the experiment starts with the sample preparation. The substrate was cleaned with acetone to remove dust and contamination from the upper surface. All these clearings of samples were carried out in a small $(50 \mathrm{ml})$ borosil beaker in an ultrasonic cleaner (Sonica $2200 \mathrm{MH}$, Italy, Frequency: $45 \mathrm{kHz}$ ). The samples were etched with $\mathrm{HCl}+\mathrm{HNO}_{3}+\mathrm{H}_{2} \mathrm{O}$ at (1:1:1) ratio for 15 minutes under ultrasonic cavitation action to remove cobalt present at the surface of the samples shown in Table 2. Due to this pretreatment, the cobalt 
Table 1. Deposition condition.

Deposition parameters

Substrate

Filament

Filament temperature

Seeding Powder

Filament to substrate distance

Substrate temperature

Gas composition

Chamber reaction pressure

Deposition time

Water chillers Temp.
WC-6 wt.\% ISO K10 Sandvik cemented carbide insert

Tungsten wire $(\varnothing 0.25 \mathrm{~mm})$ carburized

$2050{ }^{\circ} \mathrm{C}$

$0.50 \mu \mathrm{m}$ Diamond Powder

$10 \mathrm{~mm}$

$700{ }^{\circ} \mathrm{C}$

$1 \% \mathrm{CH}_{4}$ in $\mathrm{H}_{2}$

20 Torr

$8 \mathrm{hr}$

$12{ }^{\circ} \mathrm{C}$
Table 2. Chemical pretreatments of $\mathrm{WC}-\mathrm{Co}$ substrates.

\begin{tabular}{ll}
\hline Treatment & Etching reagent \\
\hline Treat 1 & $\begin{array}{l}\mathrm{HCl}+\mathrm{HNO}_{3}+\mathrm{H}_{2} \mathrm{O}(1: 1: 1) \text { for } 15 \text { minutes } \\
\text { ultrasonically }\end{array}$ \\
\hline
\end{tabular}

present at the surface of the substrate was removed, due to which small voids will be produced on the surface of the sample.

After etching, the sample was cleaned with distilled water for $15 \mathrm{~min}$ ultrasonically to clean the sample so the chemicals and diluted cobalt would washout from the surface. Then the samples were seeded with 0.50 -micron diamond powder (Diamond powder $(0.50 \mu \mathrm{m}) 99.9 \%$ pure, Sigma Aldrich) ultrasonically for $5 \mathrm{~min}$, so that the tiny diamond particles were seeded inside the voids (which are present in the outer surface). In the seeding process, a moderate amount of diamond powder mixed with isopropanol in a borosil beaker then allowed to seed ultrasonically. There should only minimum amount of the diamond powder should be present at cavity for seeding purpose, the cavity or void should not be fully filled up with diamond powder. So the samples were again ultrasonically cleaned with isopropanol alcohol for 3 min to remove the excess seeding powder. The seeding of diamond powder was carried out ultrasonically with the help of isopropanol to improve the nucleation density to a large extent. At the time of deposition, the chamber pressure was kept at 20 Torr, the temperature of the tungsten filament was kept at $2050 \pm 50^{\circ} \mathrm{C}$. This temperature was monitored by a single Ga-As laser $(630-670 \mathrm{~nm}, \quad<5 \mathrm{~mW})$ infrared pyrometer (RAYNGER 3i series) Raytek, USA. The temperature of the substrate was kept $700 \pm 20^{\circ} \mathrm{C}$ using the substrate heater and the temperature of the substrate heater was monitored using a thermocouple. The substrate surface temperature was measured using a K-type thermocouple, which was located directly underneath and touching the bottom of the substrate during deposition. The flow of the reactant gases $\mathrm{H}_{2}$ and $\mathrm{CH}_{4}$ were maintained at Table 1 and the flow of the gases was controlled by MKS, USA makes Mass Flow Controller (MFC). The deposition time was kept at $8 \mathrm{~h}$.
The PCD tool is manufactured by high pressure and high temperature (HPHT) process and its properties are controlled by cobalt binder. The proper shape is obtained by $\mathrm{CNC}$ controlled laser cutting and is induction brazed at the tooltip. The PCD tool shows excellent machining performances due to its complex manufacturing process although it is expensive.

The surface texture of the diamond which was deposited on the surface of the substrate was studied by the SEM (Scanning Electron Microscope SU3500 Hitachi, Japan make). The phase structure of the thin film diamond was analyzed by XRD (X-ray Diffraction, PAN alytical's X'Pert, The Netherland) with glazing angle facility was employed to identify the presence of diamond on the surface of the WC tool insert. The XRD patterns were collected using $\mathrm{Cu}-\mathrm{k} \alpha$ target, at 0.05 step in $2 \theta$ region from 20 to $100^{\circ}$. After diamond coating, the coated tool was compared with the uncoated tool and natural diamond tool (PCD) tool. Rolled aluminum of diameter $200 \mathrm{~mm}$ and length $600 \mathrm{~mm}$ is taken for machining. Before starting the experiment to minimise the surface irregularities of the work-piece an initial turning take place. The machining of aluminium is perform by using precision Gottwaldov R5 Capstan and turret lathe. In this research work, three different velocities $(200,250,325 \mathrm{~m} / \mathrm{min})$, three feed rates $(0.09,0.12,0.18 \mathrm{~mm} / \mathrm{rev}$.$) and one Depth of Cut of$ $0.2 \mathrm{~mm}$ were taken. The cutting conditions were mentioned in Table 3. The tool inserts and tool holder specifications were provided in Table 4 .

The 3D-Kistler dynamometer, Switzerland (model 9257B), charge amplifier (model 5070A), data accusation card (model NI-ENET-9163, USA) attached with a labview-2015 software were used for the measurement of static and dynamic cutting forces. The mean surface roughness $(R a)$, Average peak to valley height $(R z)$ and maximum roughness $\left(R_{\max }\right)$ were measured after each operation by using Tylor Hobson, UK (Subtonic 25) talysurf surface roughness tester. All the tests were carried out with keeping cut-off length as $0.8 \mathrm{~mm}$, evaluation length of $4.0 \mathrm{~mm}$ and range of $100 \mu \mathrm{m}$. The images of the cutting edges and tool wear were taken by using SEM. The images were taken at $20^{\circ}$ angles with horozontal plane for isometric view of the cutting edge including rake and 
Table 3. Description of cutting condition.

\begin{tabular}{lll}
\hline Sl. No. & Cutting condition & Description \\
\hline 1. & Workpiece & $\begin{array}{l}\text { Rolled Aluminium } \\
\text { CVD Diamond coated WC Tool } \\
\end{array}$ \\
2. & Cutting Inserts & Polycrystalline Diamond (PCD) \\
& & WC (SPGN) \\
3. & Diameter of work-piece & $200 \mathrm{~mm}$ \\
4. & Length of work-piece & $600 \mathrm{~mm}$ \\
5. & Cutting Speed (v) & $200,250,325(\mathrm{~m} / \mathrm{min})$. \\
6. & Feed (f) & $0.09,0.12,0.18(\mathrm{~mm} / \mathrm{rev})$. \\
7. & Depth of cut (d) & $0.2 \mathrm{~mm}$ \\
8. & Machining Environment & Dry \\
9. & Run out in head stock & $5 \mu \mathrm{m}$ \\
10. & Run out in tail stock & $10 \mu \mathrm{m}$ \\
\hline
\end{tabular}

Table 4. Cutting tool materials and tool holder specification.

\begin{tabular}{llll}
\hline Sl. No. & Cutting tool materials & Signification & Tool holder \\
\hline 1. & HF-CVD Diamond coated WC Tool (MCD) & SPGN120308 & CSBPR 2525M 12 \\
2. & $\begin{array}{l}\text { Polycrystalline Diamond (PCD) } \\
\text { brazed on WC (K-10) insert }\end{array}$ & SPUN120304 FP CD 10 & CSBPR 2525M 12 \\
3. & Cemented Carbide (WC) & SPGN120308 & CSBPR 2525M 12 \\
\hline
\end{tabular}

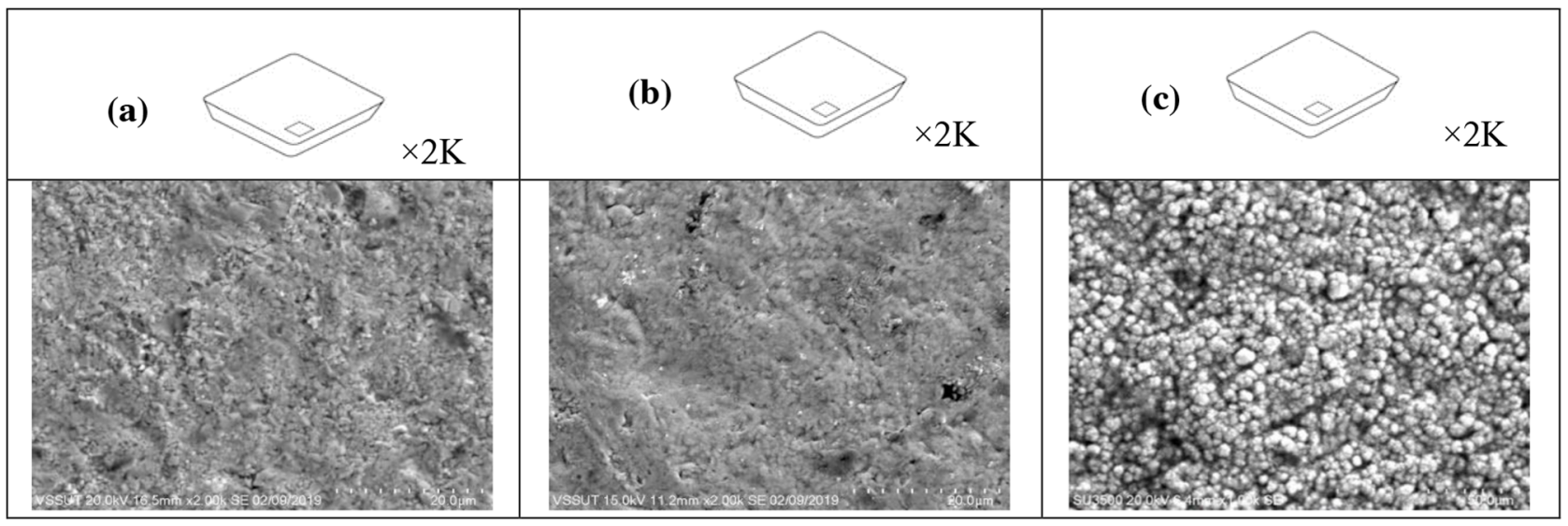

Fig. 1. SEM surface morphology of (a) after pretreatment, (b) after seeding and (c) showing the nucleation of grains.

flank surface of the tool inserts. The tool wear was analyzed by studying the SEM images. All the results were compared after completion of the experiment.

\section{Results and discussion}

The cobalt present at the surface was reduced by etching with chemicals, which was shown in Figure 1a. The top surface becomes rough and small voids were observed throughout the surface of the substrate due to the removal of the cobalt from the surface of the substrate. These voids provide space for the nucleation and growth of diamond. The seeding process is carried out by using $0.50 \mu \mathrm{m}$ size natural diamond powder after pretreatment. The diamond seeding powders are agitated into the voids shown in Figure 1b. The nucleation stage during deposition has shown in Figure 1c after one (1) hour reaction. Now growth of crystal takes place after nucleation. 


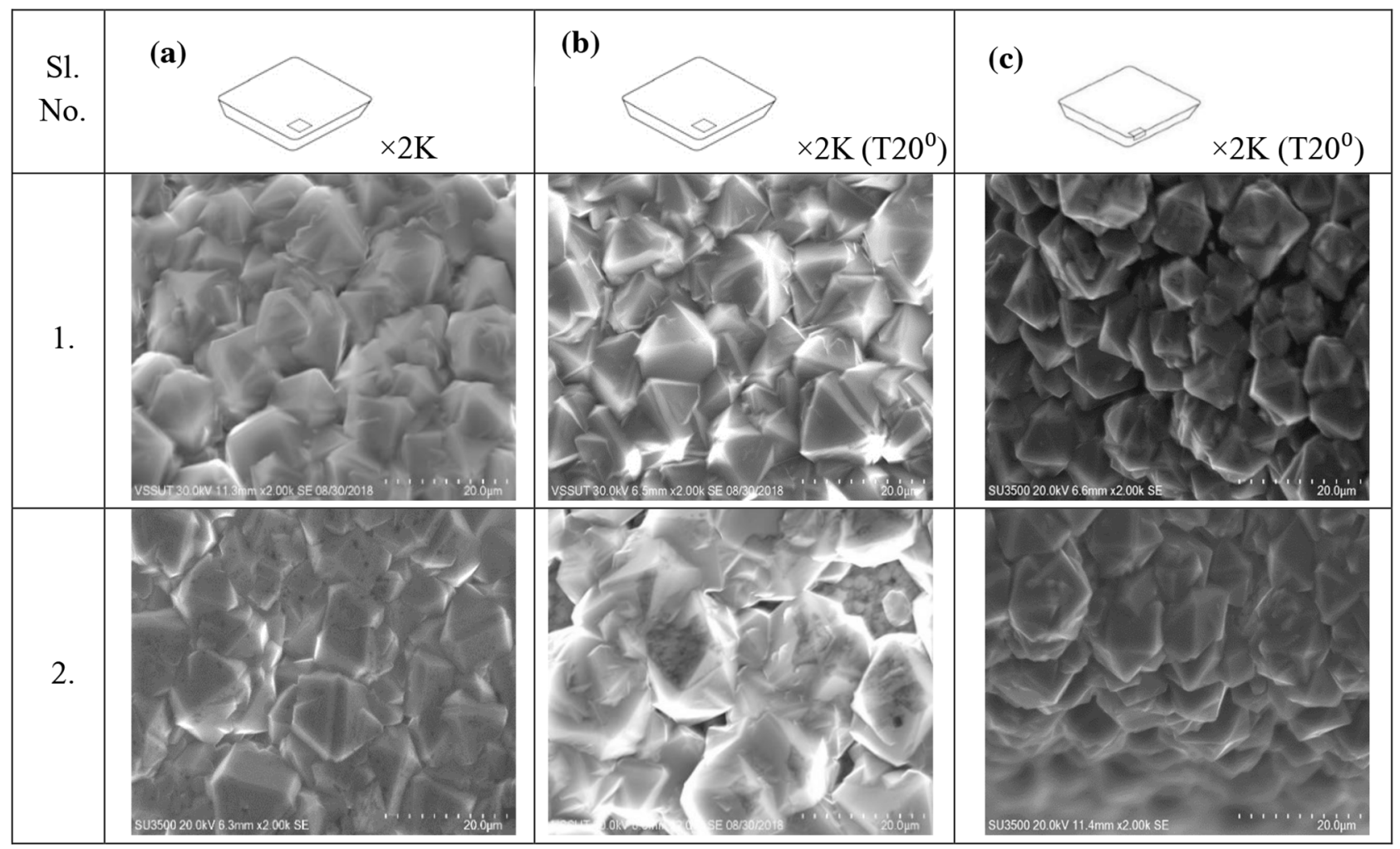

Fig. 2. SEM micrographs showing coating at the (a) surface area (b) surface at $20^{\circ}$ angles (c) nose of the cutting tool at $20^{\circ}$ angle.

Uniform micro-crystalline diamond crystals are formed after completion of eight hours reaction on the surface of the cutting tool and shown in Figure 2a. A smooth and uniform diamond crystals are quite essential during the deposition for the cutting tool. The SEM micrographs were taken with $20^{\circ}$ angles with hozontal plane to make three dimensional view and shown in Figure 2b. The SEM micrographs were taken at the nose of tool inserts show the rake and flank surfaces of the cutting tool and shown in Figure 2c. A uniform coating was produced with better step coverage. The rake face comes in contact during machining operation with the chip whereas the flank surface comes to contact with the workpiece. So a uniform coating is very much essential at the nose area of cutting tool to avoid tool wear. The hard and low friction coating minimize the wear rate of the cutting tool.

\subsection{Cutting tool characterization}

In the case of HFCVD coated MCD tool insert which is shown in Figure 3 the WC peaks appeared at angle $31.3^{\circ}$, $36.7^{\circ}, 48.4^{\circ}, 64.30^{\circ}, 73.8^{\circ}$ with different planes (001), (100), (101), (110) and (111) respectively. The weak (111) and (220) diamond peaks appeared at angle $44.18^{\circ}$ and $77.67^{\circ}$. The XRD pattern of PCD tool shows availability of strong (111) and (220) planes at $44.18^{\circ}$ and $77.67^{\circ}$ diffraction angle. XRD image of WC substrate shows different peaks at their respective diffraction angle. They are (001), (100), (101), (110), (111) planes and observed at diffraction angle of $31.3^{\circ}, 36.7^{\circ}, 48.4^{\circ}, 64.30^{\circ}, 73.8^{\circ}$ respectively.

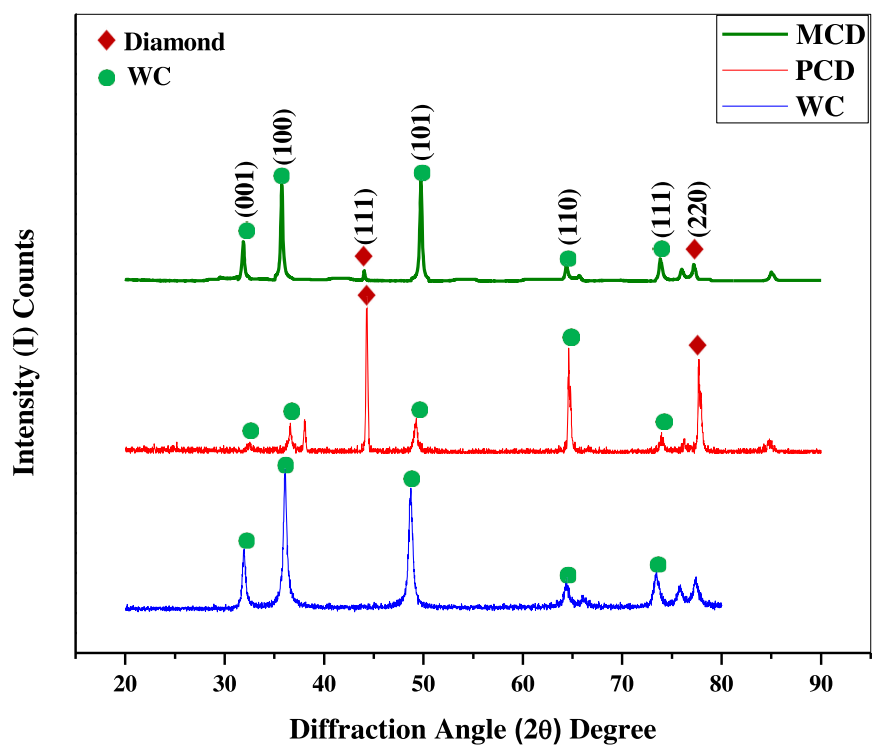

Fig. 3. XRD image of tool inserts.

\subsection{Raman spectroscopy analysis of MCD}

The Figure 4 shows the carbon phases are not supersaturated at the initial phases which help to the formation of amorphous picks. Graphite picks are the amorphous picks that are hugely present in the diamond seeded coated tool. The diamond peak for diamond seeded coated tool was 


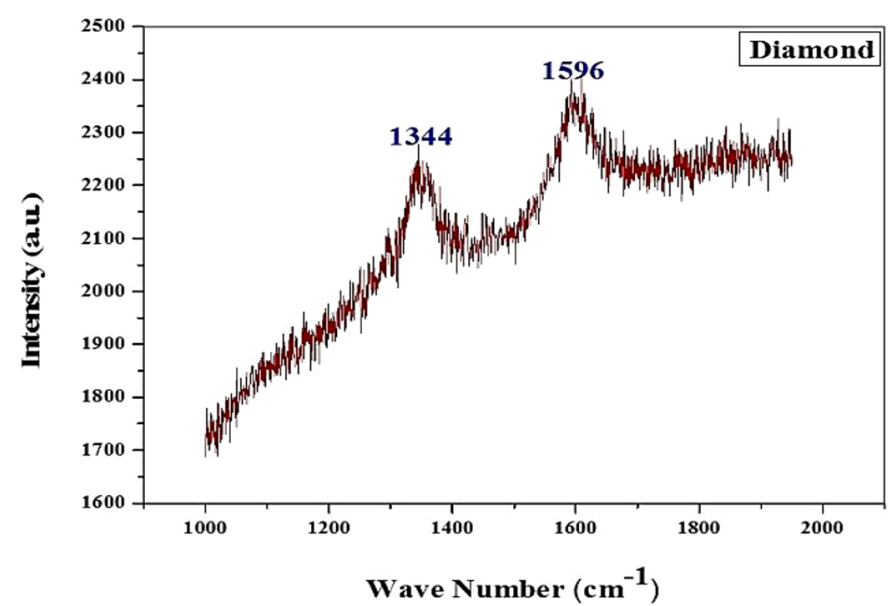

Fig. 4. Raman spectroscopy analysis of MCD insert.

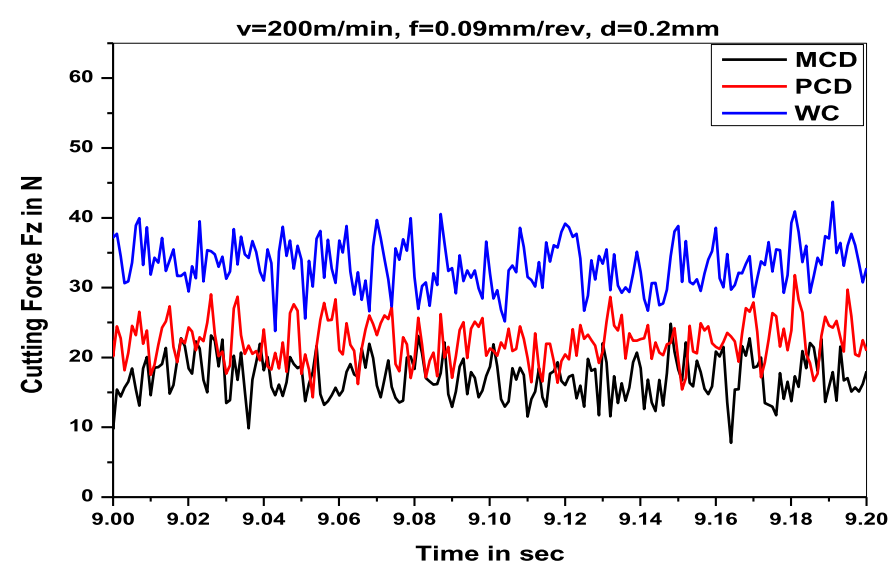

Fig. 5. Dynamic component of cutting force vs. time graph at $v=200 \mathrm{~m} / \mathrm{min}, f=0.09 \mathrm{~mm} / \mathrm{rev}, d=0.2 \mathrm{~mm}$.

observed at $1344 \mathrm{~cm}^{-1}$ wave number with having higher intensity as 2250 a.u.. The strong peak of diamond is due to the presence of microcrystalline diamond crystals.

\subsection{Cutting force}

The measurement of cutting force is very essential during machining. The cutting force directly affects the surface roughness and tool life. The dynamic component of cutting force is taken and shown in Figures 5-13 at different cutting conditions during machining. The sampling rate was taken as $1 \mathrm{k} / \mathrm{s}$. The run-out measured at headstock is $5 \mu \mathrm{m}$ and on the tailstock side is $10 \mu \mathrm{m}$ were taken for machining process.

It is clearly shown from Figure 14 that by increasing feed rate during machining, the force value increases. Figure 14a shows at constant velocity $(200 \mathrm{~m} / \mathrm{min})$ with respect to varying feed rates like $0.09,0.12,0.18 \mathrm{~mm} / \mathrm{rev}$ the force produced was higher in case of WC insert in

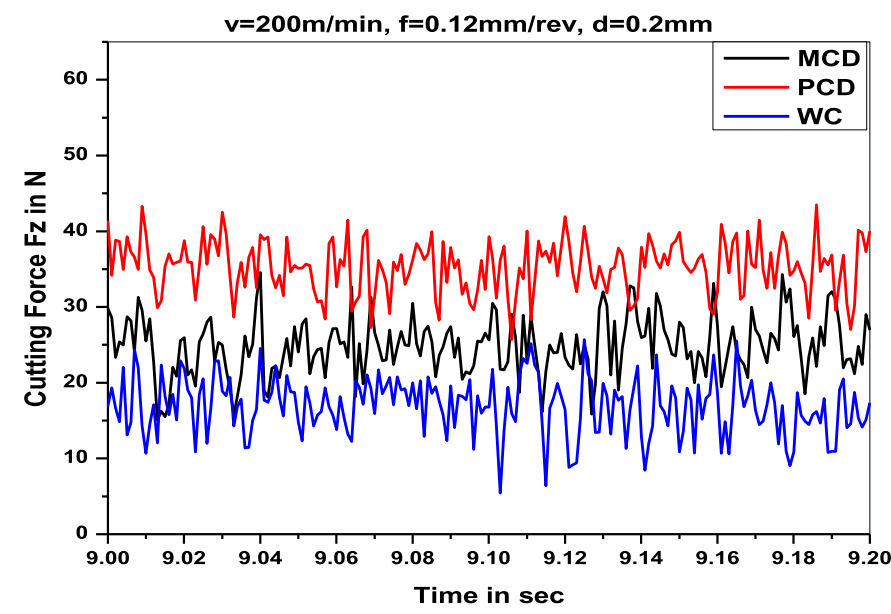

Fig. 6. Dynamic component of cutting force vs. time graph at $v=200 \mathrm{~m} / \mathrm{min}, f=0.12 \mathrm{~mm} / \mathrm{rev}, d=0.2 \mathrm{~mm}$.

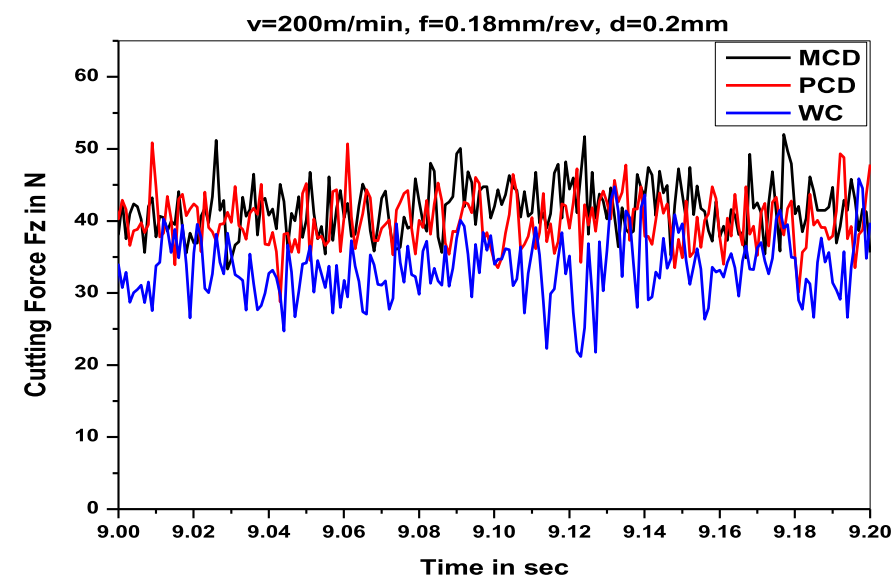

Fig. 7. Dynamic component of cutting force vs. time graph at $v=200 \mathrm{~m} / \mathrm{min}, f=0.18 \mathrm{~mm} / \mathrm{rev}, d=0.2 \mathrm{~mm}$.

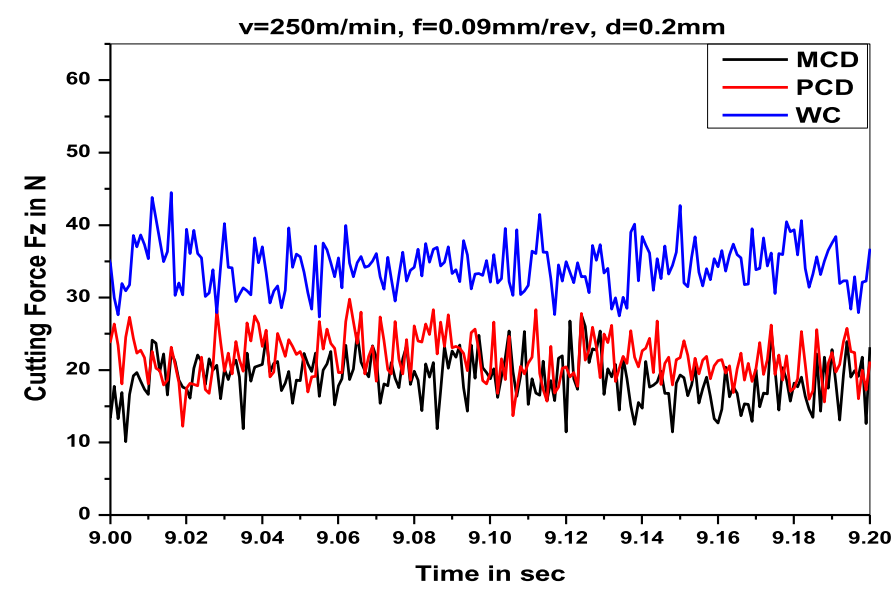

Fig. 8. Dynamic component of cutting force vs. time graph at $v=250 \mathrm{~m} / \mathrm{min}, f=0.09 \mathrm{~mm} / \mathrm{rev}, d=0.2 \mathrm{~mm}$. 


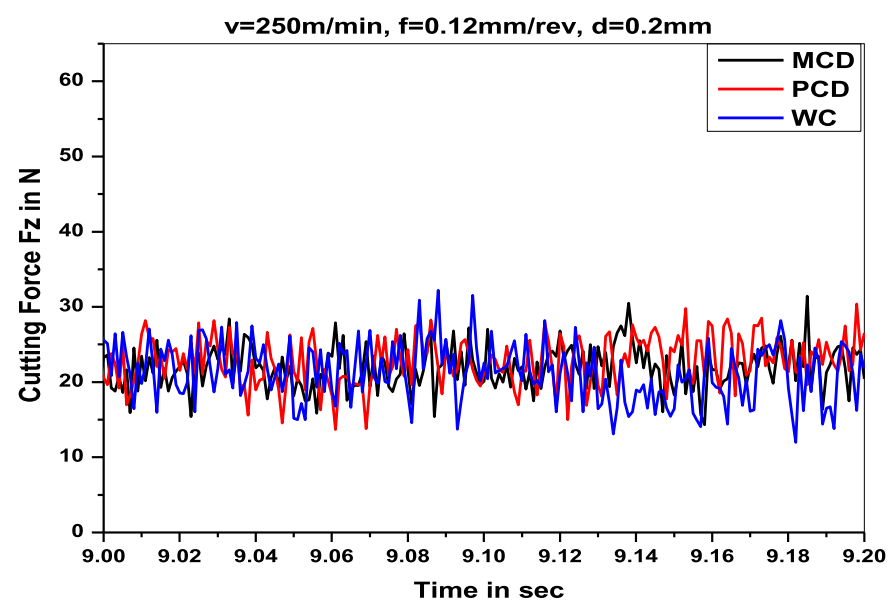

Fig. 9. Dynamic component of cutting force vs. time graph at $v=250 \mathrm{~m} / \mathrm{min}, f=0.12 \mathrm{~mm} / \mathrm{rev}, d=0.2 \mathrm{~mm}$.

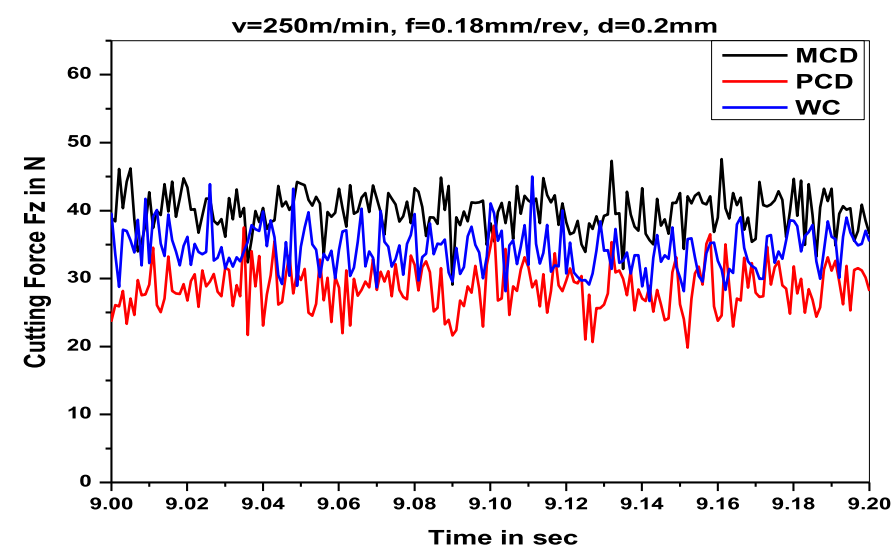

Fig. 10. Dynamic component of cutting force vs. time graph at $v=250 \mathrm{~m} / \mathrm{min}, f=0.18 \mathrm{~mm} / \mathrm{rev}, d=0.2 \mathrm{~mm}$.

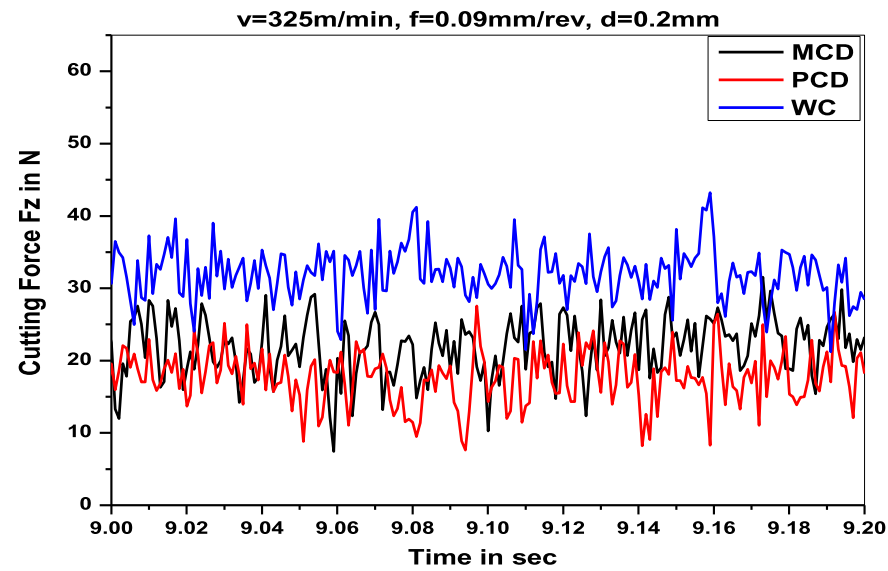

Fig. 11. Dynamic component of cutting force vs. time graph at $v=325 \mathrm{~m} / \mathrm{min}, f=0.09 \mathrm{~mm} / \mathrm{rev}, d=0.2 \mathrm{~mm}$.

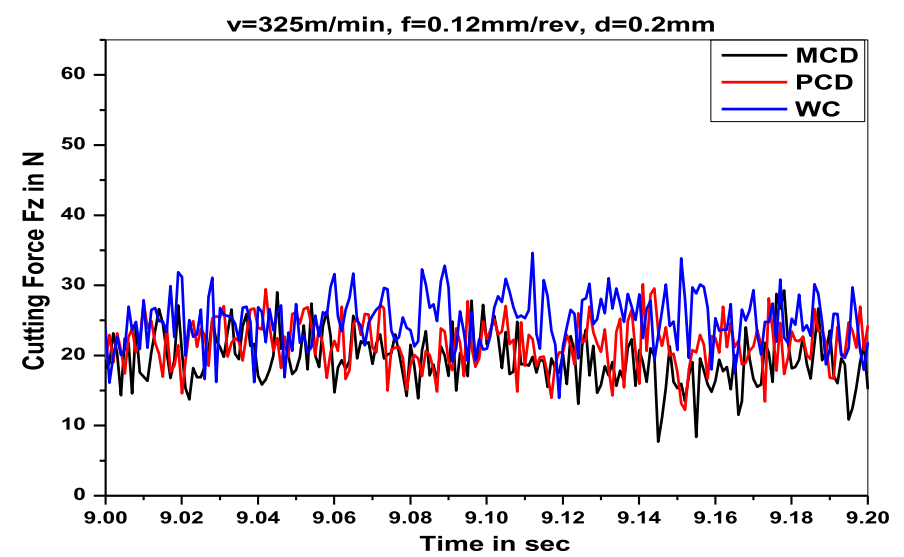

Fig. 12. Dynamic component of cutting force vs. time graph at $v=325 \mathrm{~m} / \mathrm{min}, f=0.12 \mathrm{~mm} / \mathrm{rev}, d=0.2 \mathrm{~mm}$.

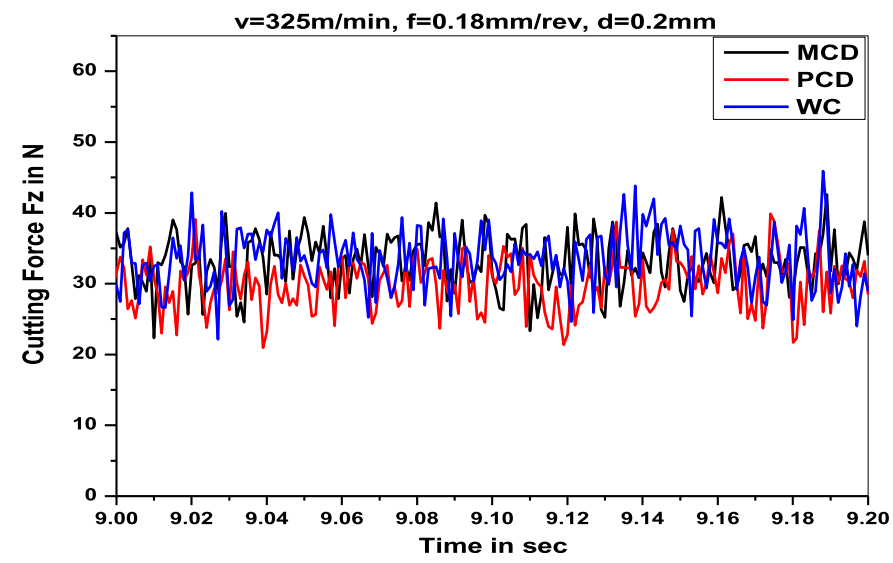

Fig. 13. Dynamic component of cutting force vs. time graph at $v=325 \mathrm{~m} / \mathrm{min}, f=0.18 \mathrm{~mm} / \mathrm{rev}, d=0.2 \mathrm{~mm}$.

comparison of MCD and PCD tool. It is clearly observed from Figures $14 \mathrm{a}-\mathrm{c}$ that the MCD tool give better performance with respect to both WC and PCD tool. The lowest force is achieved in MCD tool insert and highest force is located in $\mathrm{WC}$ tool insert. The PCD gives equivalent performance near to MCD tool. The WC tool shows higher force at 250 and $325 \mathrm{~m} / \mathrm{min}$ in both cases, which are shown in Figure 14b and c. MCD tool shows better performance at low feed rate. This means less force value than that of $\mathrm{PCD}$ tool but at higher feed rate $(0.18 \mathrm{~mm} / \mathrm{rev})$ the MCD insert show higher force value than PCD tool. The results confirm initially at low feed rate due to low friction, minor tool wear has take place. But, at higher feed due to high tool wear, coating thickness decreases.

Figure $15 \mathrm{a}-\mathrm{c}$ represents the graphs for cutting force at a constant feed rate and varying cutting velocities. It shows that by increasing velocity at constant feed rate the cutting force decreases. The performance of $\mathrm{WC}$ tool is poor as compared to the MCD and PCD tools. It is observed that the cutting forces in the case of PCD and MCD tools are lesser than that of $\mathrm{WC}$ tool. It is due to the friction in 


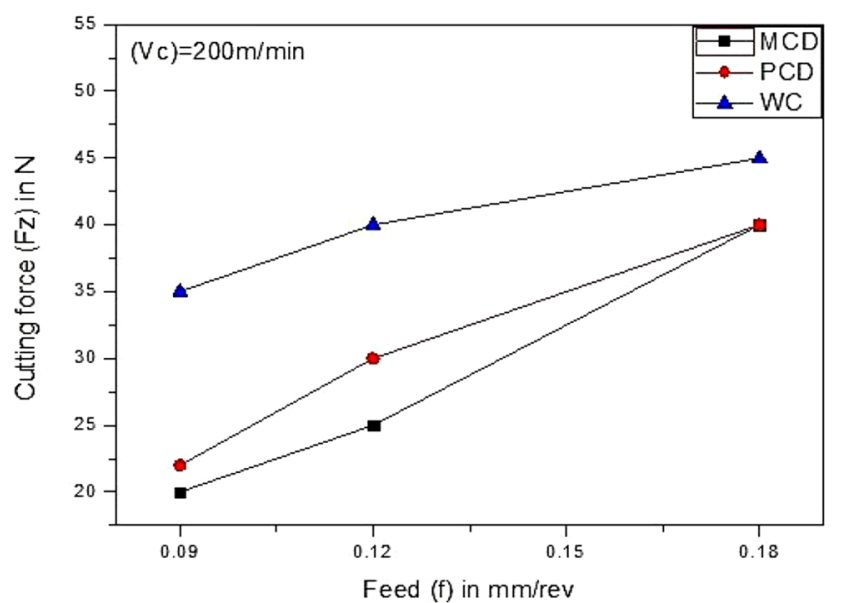

(a)

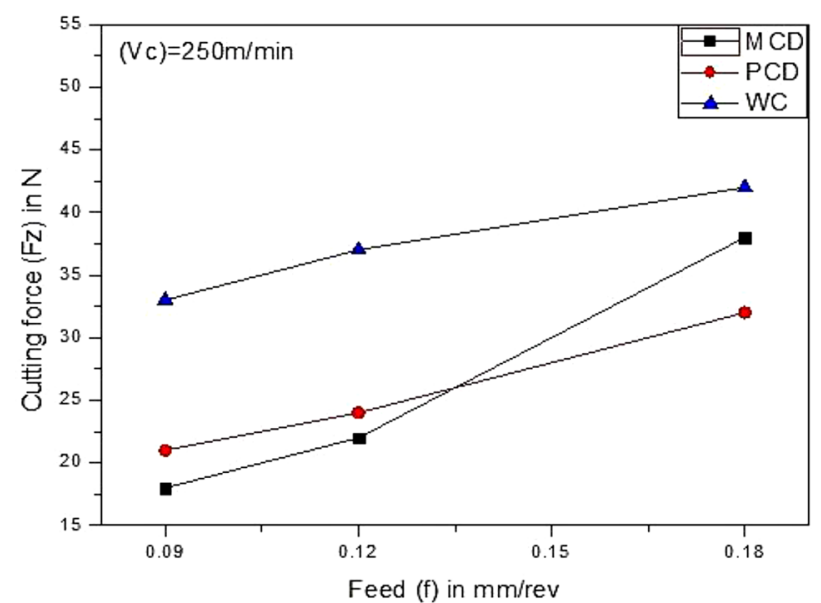

(b)

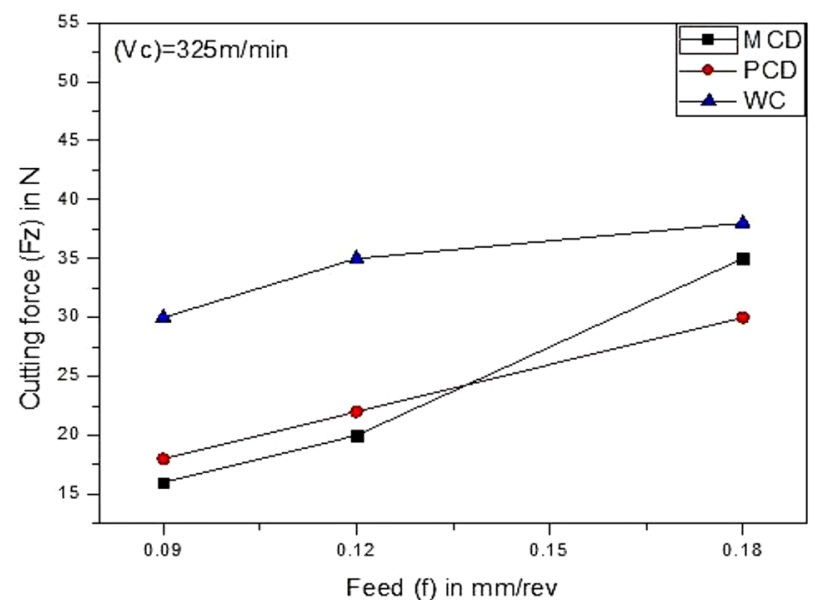

(c)

Fig. 14. Graph representing the cutting force values at various feed $0.09 \mathrm{~mm} / \mathrm{rev}, 0.12 \mathrm{~mm} / \mathrm{rev}$ and $0.18 \mathrm{~mm} / \mathrm{red}$ with constant cutting speed (a) $200 \mathrm{~m} / \mathrm{min}$, (b) $250 \mathrm{~m} / \mathrm{min}$ and (c) $325 \mathrm{~m} / \mathrm{min}$ respectively.

the interface of the tool and work-piece is less in the case of PCD and MCD tools while comparing with WC tool. The thermal conductivity of brazed diamond and CVD coated diamond tool is very high compared to the WC tool. The formation of BUE and chipping in case of diamond tool is negligible compared to the carbide tool. It has been found in Figure 15a that the MCD tool produced minimum cutting force compared to WC and PCD tools. The cutting force produced by the PCD tool is closer to the MCD tool whereas a very high cutting force is obtained for WC tool. In Figure 15b a similar type of condition can be observed. It has been further noticed from Figure 15c that at velocity $325 \mathrm{~m} / \mathrm{min}$. and feed $0.18 \mathrm{~mm} / \mathrm{rev}$. PCD tool produced very less amount of cutting force.

\subsection{Surface roughness}

Calculation of surface roughness is vital in checking quality of the product in modern machining processes. The surface finish quality was obtained after each turning process. This is another primary aspect of the final product. The surface finish depends on various cutting parameters, tool material and also in work-piece material. The cost of the final product also depends on the level of surface finish. Three readings were taken for each experiment to avoid measurement errors along an axis parallel to the axis of the work-piece. The roughness values were measured at three different locations on the work-piece. The average value of the three measurements were considered. Ra at constant speed $(200 \mathrm{~m} / \mathrm{min})$ and various feed rates $(0.09,0.12,0.18 \mathrm{~mm} / \mathrm{rev}$. respectively) were shown in Figure $16 \mathrm{a}-\mathrm{c}$. The PCD tool produced better surface at low feed rate $(0.09 \mathrm{~mm} / \mathrm{min})$ which was expected. The Ra also increased with increase in feed rate thus increase in surface roughness. The WC cutting tool produced an average surface finish. The MCD tool produced low surface finish among all cutting tools. This is because after etching, the nose of the cutting tool became rough (due to the removal of $\mathrm{Co}$ ) and after coating the diamond grains were projected outward, which can be seen from Figure $2 \mathrm{~b}$. So the MCD tool produced low surface finish compared to WC and PCD tools. The surface roughness was minimum in case of WC cutting tool at low feed rate $(0.09 \mathrm{~mm} / \mathrm{rev}$.) but at higher feed rates it produced average surface finish 


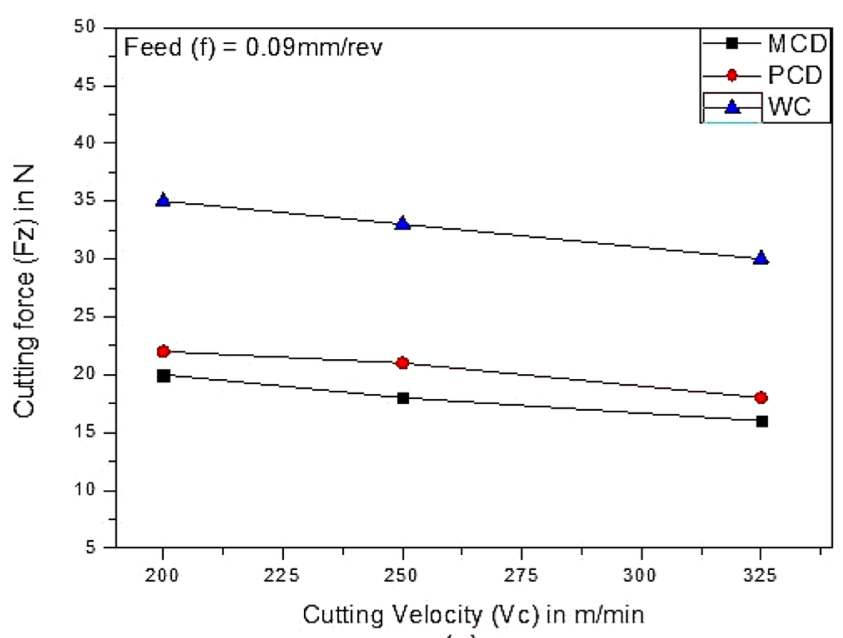

(a)

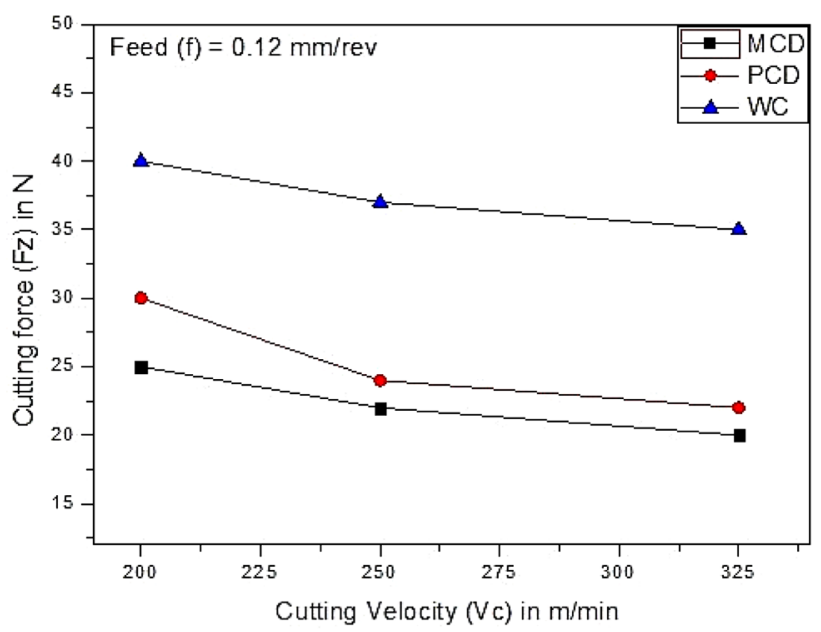

(b)

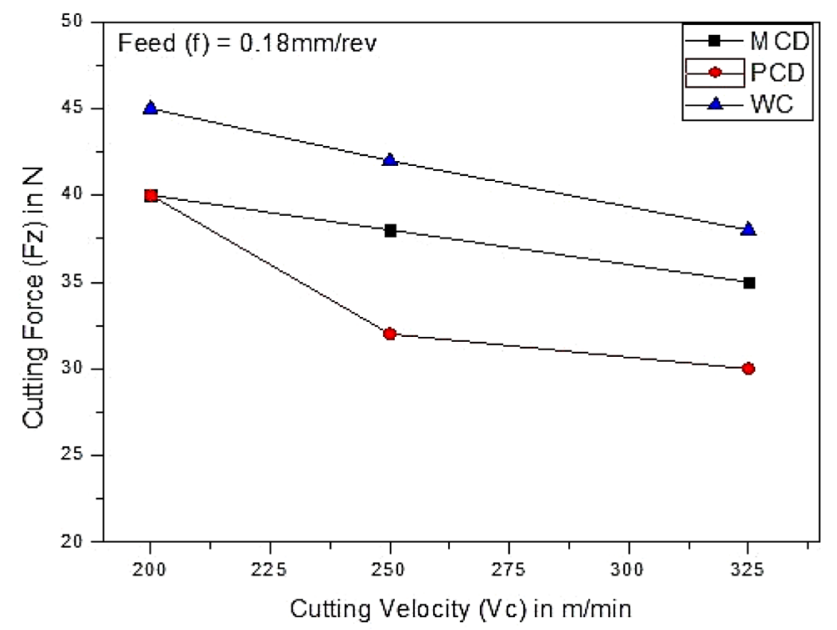

(c)

Fig. 15. Graph representing the cutting force values at various speed $200 \mathrm{~m} / \mathrm{min}, 250 \mathrm{~m} / \mathrm{min}$ and $325 \mathrm{~m} / \mathrm{min}$ with constant cutting feed (a) $0.09 \mathrm{~mm} / \mathrm{rev}$, (b) $0.12 \mathrm{~mm} / \mathrm{rev}$ and (c) $0.18 \mathrm{~mm} / \mathrm{rev}$ respectively.

similar to the other cutting tools shown in Figure $17 \mathrm{a}-\mathrm{c}$. But still, the WC tool produced better surface finish at medium speed ( $250 \mathrm{~m} / \mathrm{min}$.). It has been found from MCD and PCD tools, that both of them have produced an almost similar surface finish shown in Figure $18 \mathrm{a}-\mathrm{c}$. However, at higher feed rate $(0.18 \mathrm{~mm} / \mathrm{rev}$.$) , the MCD tool shows$ better surface finish compared to the PCD tool. The uncoated WC tool produced better surface finish at higher speed $(325 \mathrm{~m} / \mathrm{min}$.$) and low feed (0.09 \mathrm{~mm} / \mathrm{rev}$.$) . But$ surprisingly at medium $(0.12 \mathrm{~mm} / \mathrm{rev})$ and high $(0.18 \mathrm{~mm} /$ rev) feed rate, the MCD tool produced comparatively better surface finish among all. The PCD tool produced almost an average surface finish.

\subsection{Tool wear analysis}

The study of tool wear in case of machining is vital to know the tool life of the tool. Tool wear occurs at the nose radius, rake face, flank face as well as on trailing clearance face. There are various types of wear mechanism occurs during machining process. This wear pattern provides lots of information about the effectiveness of the machining operation. The tool wear is directly proportional to the tool life. Tool life is also affected by factors like cutting forces, surface roughness, chip control, accuracy and precision as well as the economy of the machining operation. The wear mainly occurs due to the adhesion and diffusion of $\mathrm{Al}$ on tool surfaces. Cutting tools generally fail by quick dulling, mechanical breakage and gradual wear at the chip-tool and work-tool interfaces. The first two methods of premature failure could be almost eliminated by the development of tool materials, selection of tool geometry, cutting parameters and cutting environments. However, the tool failure which is inevitable cannot be prevented but it can be delayed only. The basic mechanisms of tool wear are flank, crater and abrasive wear.

The tool wear study was performed after completion of machining processes. Each tool was used in machining for 270 s. It can be observed from Figure 19a that, in the case of MCD small amount of sliding lines have been formed over 


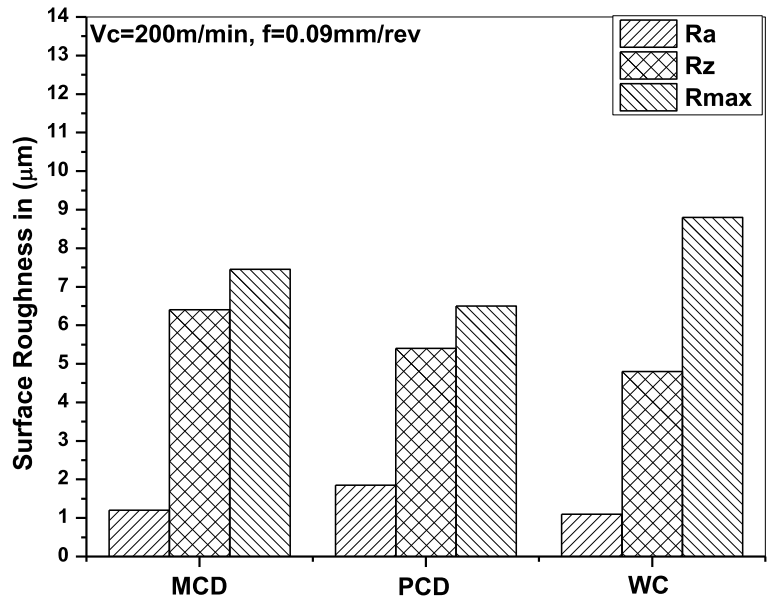

(a)

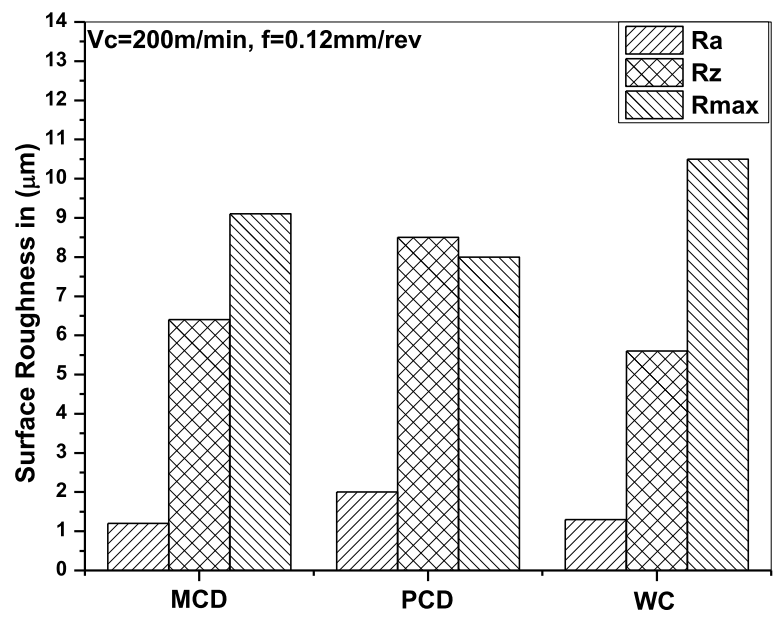

(b)

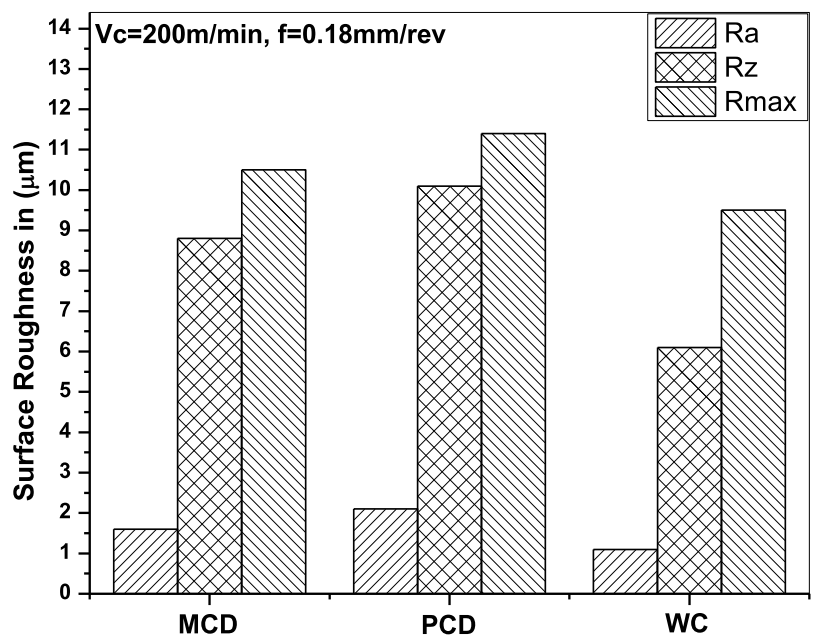

(c)

Fig. 16. Graph representing the roughness values $\left(R a, R z, R_{\max }\right)$ for different tools at constant velocity of $200 \mathrm{~m} / \mathrm{min}$ and varying feed, (a) Feed $=0.09 \mathrm{~mm} / \mathrm{rev}$, (b) Feed $=0.12 \mathrm{~mm} / \mathrm{rev}$ and (c) Feed $=0.18 \mathrm{~mm} / \mathrm{rev}$; constant depth of cut $0.02 \mathrm{~mm}$.

the rake surface and some amount of upper layer of the tool face is being removed. The tool nose or tip has negligible chamfering due to small nose wear. The Figure 19b shows SEM image depicting the rake faces of PCD tool. In case of PCD tool a small amount of tooltips got damaged and no sliding lines are visible on the rake face. There is no sticking of any extra material over rake and flank face. A large number of sliding lines have been formed over the rake surface and the upper layer of the tool face was removed in WC insert. The measure chamfering of tooltip was located in Figure 19c. It was a clear evidence of sticking of some extra material on the flank face. But the presence of aluminum is slightly high compared to MCD insert. This is caused due to formation of built-up edge (BUE).

It was clear evidence of sticking of some extra material on the flank face but the amount of extra material was very small compared to WC insert. Thus, MCD insert gets less wear than WC but higher than PCD tool.

\subsection{Chip underface}

Aluminum and its alloys are industrially known as ductile material which provides continuous chips. During machining, continuous chip provides more friction between tool rake face and chip which may affect the tool and chip underface. The chemical reaction between the tool rake and chip increases due to friction which hinders smooth flow of chips. This causes formation of micro cracks in chip underface. It can be observed from Figure 20 that the continuous feed and sliding marks are shown in case of the MCD tool. In the case of PCD tool, smooth regular feed marks at regular interval are shown with no appearance of 


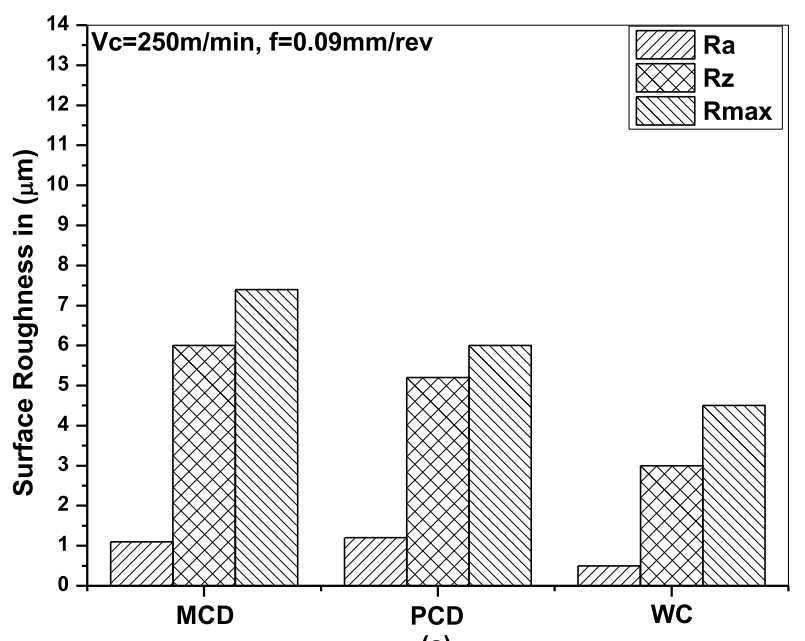

(a)

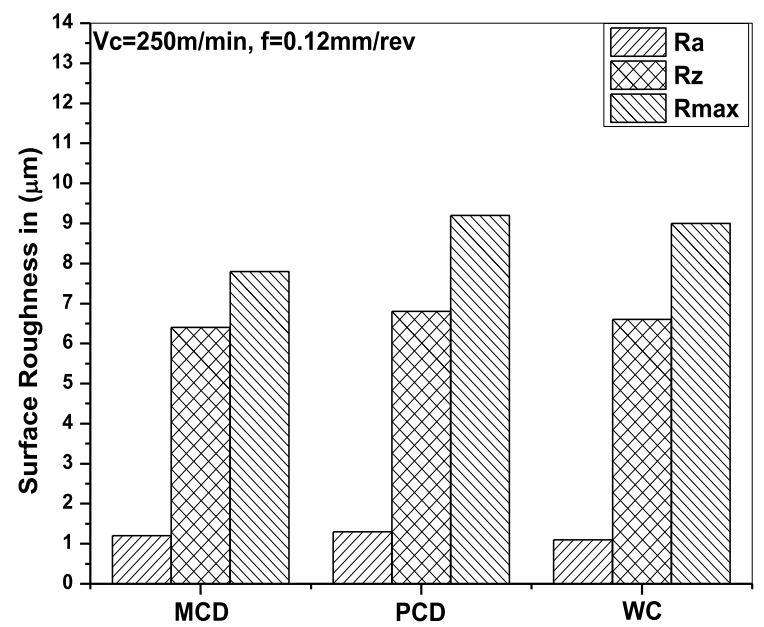

(b)

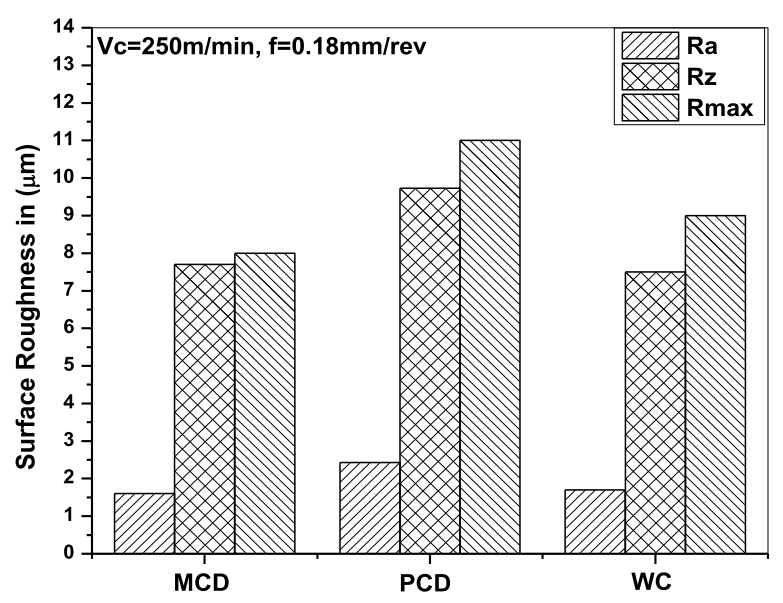

(c)

Fig. 17. Graph representing the roughness values $\left(R a, R z, R_{\max }\right)$ for different tools at constant velocity of $250 \mathrm{~m} / \mathrm{min}$ and varying feed, (a) Feed $=0.09 \mathrm{~mm} / \mathrm{rev}$, (b) Feed $=0.12 \mathrm{~mm} / \mathrm{rev}$ and (c) Feed $=0.18 \mathrm{~mm} / \mathrm{rev}$.

cracks or micro voids. This tends to no adhesion of aluminum during machining. The $\mathrm{WC}$ tool contains nonuniform sliding marks and more number of micro cracks. The white spots located in the underface due to adhesion of aluminum during machining.

\section{Conclusion}

In this paper, MCD film was deposited on WC cutting tool inserts for turning aluminium. Two other cutting tools (WC, PCD) were also used for the same to compare and to find out the suitability of the coated tools.

- Specifically, it was found that the $\mathrm{WC}$ and $\mathrm{PCD}$ produced better surface finish compared to the MCD tool. However at high speed and low feed rate (finishing operation), it showed promising results.

- Regarding force measurement, a minimum cutting force was produced while machining with the MCD cutting tool which is an indication of providing maximum tool life.

- The analysis of tool wear (by the study of SEM images) represents that, the wear occurred on the PCD tool was less compared to MCD and WC tools. Nevertheless, the performance of the MCD tool is quite impressive, because negligible wear occurred after machining.

- In chip underface study, it was observed that less destruction produced with the PCD tool. So it indicates that less tool wear was formed in PCD tool. In this study also a promising result was observed with using MCD tool in machining.

After a complete analysis of the results, we may conclude that PCD is a better cutting tool for machining of aluminum. But when we consider overall performance with cost-effectiveness, the MCD found as the best cutting tool among all. So MCD may be recommended for the machining of aluminum and its alloys for industrial applications. 


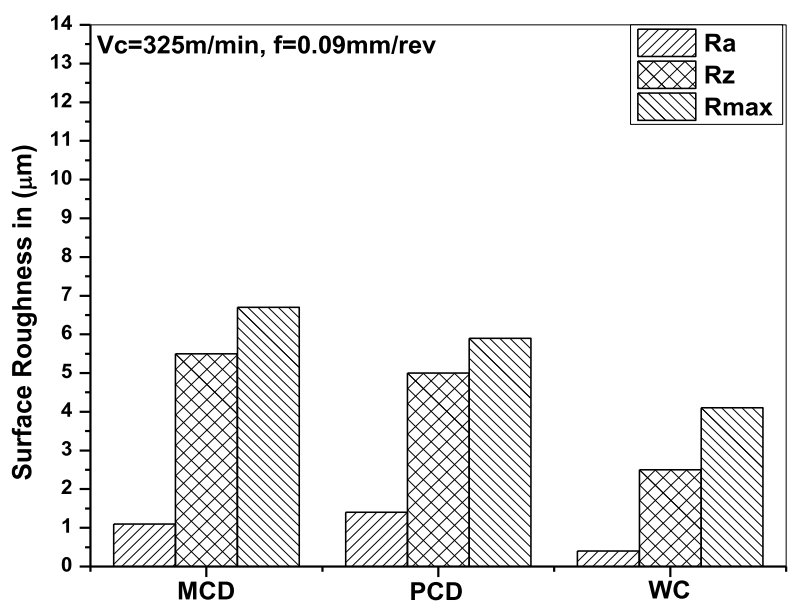

(a)

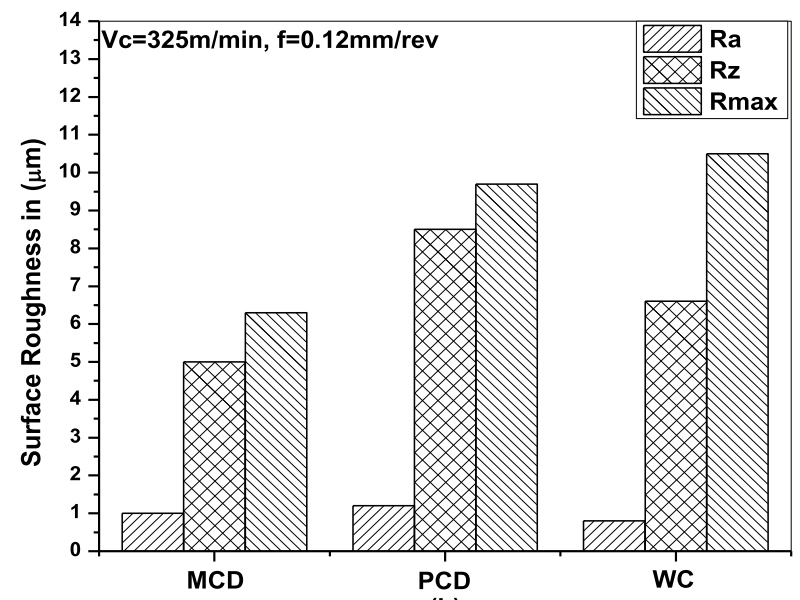

(b)

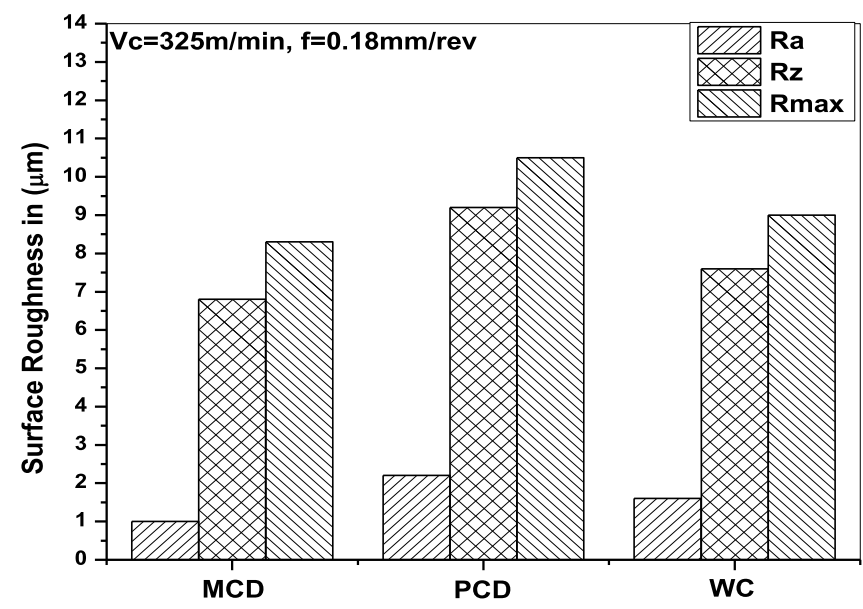

(c)

Fig. 18. Graph representing the roughness values $\left(R a, R z, R_{\max }\right)$ for different tools at constant velocity of $325 \mathrm{~m} / \mathrm{min}$ and varying feed, (a) Feed $=0.09 \mathrm{~mm} / \mathrm{rev}$, (b) Feed $=0.12 \mathrm{~mm} / \mathrm{rev}$ and (c) Feed $=0.18 \mathrm{~mm} / \mathrm{rev}$.

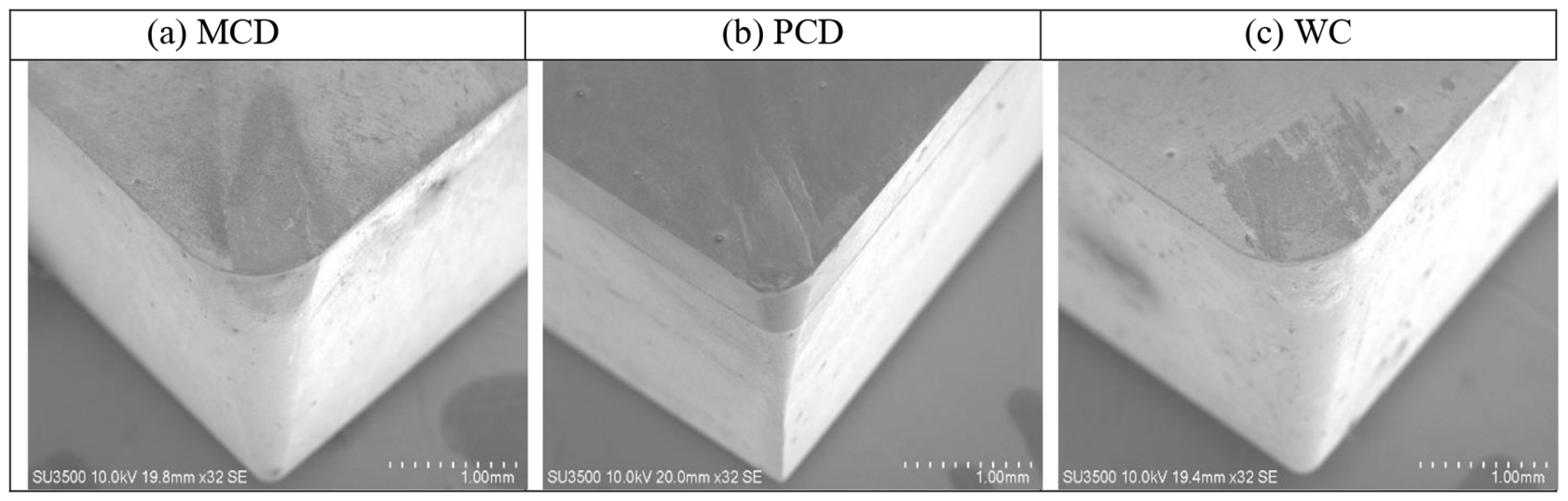

Fig. 19. SEM images of tool wear. 


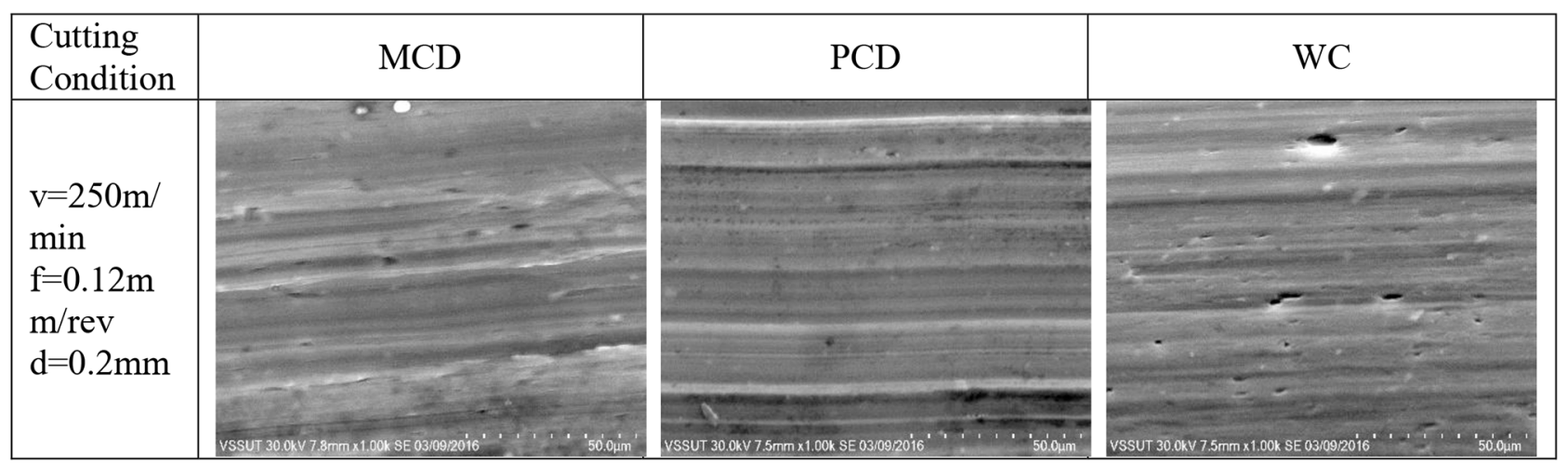

Fig. 20. SEM images of chip underface after machining.

In terms of future work, this study can be extended by using a different coated tool to establish better comparison. Further investigations can be carried out by adopting different coating techniques.

This experimental work is carried out by the support of Council of Scientific \& Industrial Research (CSIR-2013), New Delhi, India (CSIR-22(0628)/13/EMR-II). The authors would like to acknowledge all the laboratory staff of Mechanical Engineering Department, VSSUT, Burla for their kind support.

\section{References}

1. R.K. Ghadai, K. Kalita, S.C. Mondal, B.P. Swain, PECVD process parameter optimization: towards increased hardness of diamond-like carbon, Thin Films. Mater. Manuf. Process. 33 (2018) 1905-1913

2. X. Wang, C. Wang, F. Sun, C. Ding, Simulation and experimental researches on HFCVD diamond film growth on small inner-hole surface of wire-drawing die with no filament through the hole, Surf. Coatings Technol. 339 (2018) 1-13

3. K. Paprocki, A. Dittmar-Wituski, M. Trzcinski, M. Szybowicz, K. Fabisiak, A. Dychalska, The comparative studies of HF CVD diamond films by Raman and XPS spectroscopies, Opt. Mater. (Amst). 95 (2019) 109251

4. M. Aydin, Prediction of cutting speed interval of diamondcoated tools with residual stress, Mater. Manuf. Process. 32 (2027) 145-150

5. R.K. Ghadai, K. Kalita, S.C. Mondal, B.P. Swain, Genetically optimized diamond-like carbon thin film coatings, Mater. Manuf. Process. 34 (2019) 1476-1487

6. Y. Chen, D. Xiang, H. Feng, B. Wu, X. Niu, Fabrication and performance of boron doped textured diamond coated tool, Surf. Eng. (2019) 1-8

7. Y.K. Lim, E.S. Lee, C.H. Lee, D.S. Lim, Fabrication of hollow boron-doped diamond nanostructure via electrochemical corrosion of a tungsten oxide template, Nanotechnology $\mathbf{2 9}$ (2018) 325602

8. S. Matsumoto, Y. Sato, M. Kamo, N. Setaka, Vapor, deposition of diamond particles from methane, Jpn. J. Appl. Phys. 21 (1982) 183-185

9. M. Abdel-Hafiez, D. Kumar, R. Thiyagarajan, Q. Zhang, R. T. Howie, K. Sethupathi, O. Volkova, A. Vasiliev, W. Yang, H.K. Mao, High-pressure behavior of superconducting borondoped diamond, Phys. Rev. B 95 (2017) 1-7
10. W.L. Shi, X.T. Wei, W. Zhang, Z.G. Wang, C.H. Dong, S. Li, Developments and applications of diamond-like carbon, Appl. Mech. Mater. 864 (2017) 14-24

11. S.K. Sarangi, A. Chattopadhyay, A.K. Chattopadhyay, Effect of pretreatment methods and chamber pressure on morphology, quality and adhesion of HFCVD diamond coating on cemented carbide inserts, Appl. Surface Sci. 254 (2008) 3721-3733

12. Q. Wei, Z.M. Yu, M.N.R. Ashfold, J. Ye, L. Ma, Applied surface science synthesis of micro- or nano-crystalline diamond films on WC-Co substrates with various pretreatments by hot filament chemical vapor deposition, Appl. Surf. Sci. 256 (2010) 4357-4364

13. M.S. Raghuveer, S.N. Yoganand, K. Jagannadham, R.L. Lemaster, J. Bailey, Improved CVD diamond coatings on WC-Co tool substrates, Wear 253 (2002) 1194-1206

14. M. Amaral, D.J. Silva, A.J.S. Fernandes, F.M. Costa, F.J. Oliveira, R.F. Silva, Surface activation pre-treatments for NCD films grown by HFCVD, Vaccum 83 (2009) $1228-1232$

15. T. Zhang, F. Qin, W. Qian, L. Zhang, F. Sun, Characterisation of microcrystalline diamonds deposited by HFCVD. Int. J. Abras. Technol. 8 (2018) 292-309

16. K. Dejun, Z. Wen, Z. Ling, Friction-wear behaviors of chemical vapor deposited diamond films at high temperatures, J. Superhard Mater. 41 (2019) 98-105

17. R. Zhang, M. Shen, Z. He, The unusual tribological behavior of diamond-like carbon films under high vacuum, Surf. Interface Anal. (2020) 1-9

18. S. Viswanathan, L. Mohan, P. Bera, S. Shanthiswaroop, M. Muniprakash, H.C. Barshilia, C. Anandan, Corrosion and wear resistance properties of multilayered diamond-like carbon nanocomposite coating, Surf. Interface Anal. 50 (2018) 265-276

19. M. Sabzi, S.H. Mousavi Anijdan, M. Asadian, The effect of substrate temperature on microstructural evolution and hardenability of tungsten carbide coating in hot filament chemical vapor deposition, Int. J. Appl. Ceram. Technol. 15 (2018) 1350-1357

20. V.M. Kvasnytsya, I.V. Kvasnytsia, A. Zheldak, Cyclic twins of CVD diamond crystals, J. Superhard Mater. 41 (2019) 369-376

21. T. Zhang, F. Qin, L. Zhang, L. Gao, F. Sun, HFCVD synthesis of boron-doped microcrystalline diamonds, J. Superhard Mater. 41 (2019) 143-148 
22. D. Mukherjee, R. Polini, V. Valentini, S.Z. Rotter, J.C. Mendes, HFCVD nanostructured diamond films deposited by a combination of seeding suspensions and novel nucleation process, Int. J. Surf. Sci. Eng. 11 (2017) 225-240

23. S.H. Din, M.A. Shah, N.A. Sheikh, Tribological performance of titanium alloy Ti-6Al-4V via CVD-diamond coatings, J. Superhard Mater. 40 (2018) 26-39

24. Y. Xu, K. Chen, S. Wang, S. Chen, X. Chen, Influence of pretreatment on diamond-coated tool nucleation and machining performance, Surf. Rev. Lett. 24 (2017)

25. A.N. Jones, W. Ahmed, C.A. Rego, H. Taylor, B.D. Beake, M.J. Jackson, Investigation of the tribological properties of diamond films, J. Mater. Eng. Perform. 16 (2007) 131-134

26. A. Panda, S.R. Das, D. Dhupal, Machinability investigation and sustainability assessment in FDHT with coated ceramic tool, Steel Compos. Struct. 34 (2020) 681-698

27. A. Panda, S.R. Das, D. Dhupal, Machinability investigation of HSLA steel in hard turning with coated ceramic tool: assessment, modeling, optimization and economic aspects, J. Adv. Manufactur. Syst. 18 (2019) 625-655

28. U.C. Okonkwo, I.P. Okokpujie, J.E. Sinebe, C.A.K. Ezugwu, Comparative analysis of aluminium surface roughness in endmilling under dry and minimum quantity lubrication (MQL) conditions, Manufactur. Rev. 2 (2015) 30

29. A. Das, N. Tirkey, S.K. Patel, S.R. Das, B.B. Biswal, A comparison of machinability in hard turning of EN-24 alloy steel under mist cooled and dry cutting environments with a coated cermet tool, J. Fail. Anal. Prevent. 19 (2019) 115-130

30. A. Das, S.K. Patel, B.B. Biswal, S.R. Das, Machinability investigation and cost estimation during finish dry hard turning of AISI 4340 steel with untreated and cryo treated cermet inserts, J. Superhard Mater. 41 (2019) 247-264

31. J. Singh, Novel techniques for selective diamond growth on various substrates, J. Mater. Eng. Perform. 3 (1994) 78-85

32. M.J. Jackson, A.N. Jones, W. Ahmed, Experimental and gas phase modeling of nanocrystalline diamond films grown on titanium alloys for biomedical applications, J. Mater. Eng. Perform. 14 (2005) 565-568
33. H. Sein, W. Ahmed, C. Rego, M. Jackson, R. Polini, Comparative investigation of smooth polycrystalline diamond films on dental burs by chemical vapor dep.osition, J. Mater. Eng. Perform. 15 (2006) 195-200

34. R. Ahmed, A. Siddique, J. Anderson, C. Engdahl, M. Holtz, E. Piner, Selective area deposition of hot filament CVD diamond on $100 \mathrm{Mm}$ MOCVD grown AlGaN/GaN wafers, Cryst. Growth Des. 19 (2019) 672-677

35. A.F. Sartori, S. Orlando, A. Bellucci, D.M. Trucchi, S. Abrahami, T. Boehme, T. Hantschel, W. Vandervorst, J.G. Buijnsters, Laser-induced periodic surface structures (LIPSS) on heavily boron-doped diamond for electrode applications, ACS Appl. Mater. Interfaces 10 (2018) 43236-43251

36. A.P. Bolshakov, V.G. Ralchenko, V.Y. Yurov, G. Shu, E.V. Bushuev, A.A. Khomich, E.E. Ashkinazi, D.N. Sovyk, I.A. Antonova, S.S. Savin, Enhanced deposition rate of polycrystalline CVD diamond at high microwave power densities, Diam. Relat. Mater. 97 (2019) 107466

37. R. Kurniawan, T.J. Ko, A study of surface texturing using piezoelectric tool holder actuator on conventional CNC turning, Int. J. Precis. Eng. Manufactur. 14 (2013) 199-206

38. Q. Wu, D.P. Li, Analysis and X-ray measurements of cutting residual stresses in 7075 aluminum alloy in high speed machining, Int. J. Precis. Eng. Manufactur. 15 (2014) 1499-1506

39. N.V. Novikov, Superhard materials in mechanical engineering, Powder Metal. Metal Ceram. 32 (1993) 386-389

40. A. Panda, S.R. Das, D. Dhupal, Machinability investigation of HSLA steel in hard turning with coated ceramic tool: assessment, modeling, optimization and economic aspects, J. Adv. Manufactur. Syst. 18 (2019) $625-655$

41. A. Anand, A.K. Behera, S.R. Das, An overview on economic machining of hardened steels by hard turning and its process variables, Manufactur. Rev. 6 (2019) 4

Cite this article as: Sisira Kanta Pattnaik, Minaketan Behera, Sachidananda Padhi, Pusparaj Dash, Saroj Kumar Sarangi, Study of cutting force and tool wear during turning of aluminium with WC, PCD and HFCVD coated MCD tools, Manufacturing Rev. 7, $27(2020)$ 